KARASAWA, M.; RODRIGUES, R.; SUDRÉ, C.P.; SILVA, M.P.; RIVA, E.M.; AMARAL JÚNIOR, A.T. Aplicação de métodos de agrupamento na quantificação da divergência genética entre acessos de tomateiro. Horticultura Brasileira, Brasília, v.23, n.4, p.1000-1005, out-dez 2005.

\title{
Aplicação de métodos de agrupamento na quantificação da divergência genética entre acessos de tomateiro ${ }^{1}$
}

\author{
Mina Karasawa; Rosana Rodrigues; Cláudia P. Sudré; Marlon P. da Silva; Elaine M. Riva; Antônio T. do \\ Amaral Júnior \\ ${ }^{2}$ UENF/CCTA/LMGV, Av. Alberto Lamego, 2000, Parque Califórnia, 28013-600, Campos dos Goytacazes-RJ; E-mail: rosana@uenf.br
}

\section{RESUMO}

A quantificação da divergência genética entre acessos de bancos de germoplasma baseada em descritores permite a indicação de potenciais genitores a serem utilizados em programas de melhoramento, entre outros resultados de interesse para o melhorista. Para estudos de divergência genética, a análise multivariada, incluindo os métodos de aglomeração, tem sido amplamente empregada. Este trabalho teve como objetivos caracterizar e quantificar a divergência genética entre acessos de tomateiro, por meio de métodos de agrupamento. O experimento foi conduzido em 2001, em Campos dos Goytacazes, RJ., em condições de campo. Utilizou-se o delineamento experimental de blocos casualizados com 70 acessos, três repetições e 16 plantas por parcela. Vinte descritores de caracterização e cinco de avaliação foram considerados. Houve diferença significativa entre os acessos para número total, peso total, número médio, e peso médio de frutos; comprimento e diâmetro do fruto; número de dias para germinação; número de dias para frutificação; número de flores por inflorescência; teor de sólidos solúveis; número de lóculos e número de dias para florescimento, indicando a presença de variabilidade entre os acessos. O agrupamento pelo Método Hierárquico do Vizinho Mais Próximo, detectou a formação de dois grupos, baseado no número de dias para germinação. $\mathrm{O}$ grupo 1 reuniu os acessos com germinação em 10 dias e o grupo 2 foi composto pelos acessos que germinaram em sete dias. O subagrupamento dos grupos 1 e 2 permitiu a detecção de sete subgrupos no grupo $1 \mathrm{e}$ cinco subgrupos no grupo 2. O Método de Otimização de Tocher possibilitou a formação de dez grupos, concordantes com os subgrupos obtidos pelo método do Vizinho mais Próximo.

Palavras-chave: Lycopersicon esculentum, análise multivariada, caracterização de germoplasma, recursos genéticos, pré-melhoramento.

\section{ABSTRACT}

Cluster analysis in quantifying genetic divergence in tomato accessions

The quantification of the genetic divergence among accessions in a germplasm bank, based on descriptors for characterization, allows us to indicate promising parentals that can be used in breeding programs. In order to study the genetic divergence, multivariate analysis, including cluster methods has been used. The genetic divergence among tomato accessions was characterized and quantified, using cluster analysis. The experiment was carried out in 2001, in Rio de Janeiro State, Brazil, in field conditions. A randomized block design was used, with 70 accessions, three replications and 16 plants per plot. Twenty characterization and five evaluation descriptors were considered. There was significant difference among accessions for total number of fruits, total weight of fruits, mean number of fruits, mean weight of fruits, fruit length, fruit diameter, number of days for germination, days for fruit set, number of flowers per inflorescence, solid solubles, number of locules and days for flowering indicating the presence of genetic variability among accessions. Nearest neighbor method detected two groups, based on number of days for germination. Group 1 was formed by accessions with germination in 10 days while group 2 included accessions that germinated in seven days. Subgrouping from groups 1 and 2 detected seven and five subgroups for each group, respectively. Based on Tocher Method, ten groups were formed with agreement between Tocher and Nearest Neighbor.

Keywords: Lycopersicon esculentum, multivariate analysis, germplasm characterization, genetic resources, pre-breeding.

\section{(Recebido para publicação em 1 de abril de 2005 e aceito em 16 de setembro de 2005)}

$\mathrm{O}$ estudo da diversidade genética entre acessos de bancos de germoplasma fornece informações de potenciais genitores a serem utilizados em programas de melhoramento, além do fato de que a própria caracterização dos acessos possibilita a identificação de duplicatas e o intercâmbio de germoplasma entre pesquisadores. A forma preditiva de determinar a divergência genética apresenta como principal vantagem o fato de não ser necessária a obtenção prévia de combinações híbridas, como ocorre em dialelos (COIMBRA et al., 2001).

O conhecimento do grau de variabilidade genética, por meio dos estudos de divergência, torna-se vantajosa no processo de identificação de novas fontes de genes de interesse (AMARAL JÚNIOR; THIÉBAUT, 1999). Outra vantgem é o fato de que, por meio da diversidade genética, pode-se indicar progenitores geneticamente distantes para cruzamentos onde se procure obter o efeito heterótico na geração híbri- da e maior probabilidade de recuperação de segregantes superiores em gerações avançadas (AMARAL JÚNIOR; THIÉBAUT, 1999; CRUZ; REGAZZI, 2001).

Para estudos de divergência genética, a técnica de análise multivariada (componentes principais, variáveis canônicas e métodos de aglomeração) tem sido empregada tanto para características expressas por variáveis quantitativas quanto qualitativas, as quais são comumente utilizadas em caracteriza-

${ }^{1}$ Parte da tese apresentada pela primeira autora para obtenção do título de Doutor em Produção Vegetal na UENF em 2005 
ções/avaliações em bancos de germoplasma. $\mathrm{O}$ critério utilizado para a escolha do método multivariado depende do conjunto de dados, da análise a ser realizada e qual a precisão requerida (CRUZ; REGAZZI, 2001).

A variabilidade genética existente no gênero Lycopersicon tem possibilitado o desenvolvimento de cultivares que atendem às mais diversas demandas do mercado de tomate para processamento e para consumo in natura (AGRIANUAL, 2002). No entanto, anos de cultivo e seleção por melhoristas têm reduzido os níveis de variação nos germoplamas elite. Esta premissa é verdadeira para plantas autógamas, as quais possuem base genética mais estreita. Por exemplo, um estudo do polimorfismo de diversas variedades de tomate demonstrou que existem menos de $5 \%$ de variação genética disponível em cruzamentos compatíveis com variedades locais e espécies silvestres (MILLER; TANKSLEY, 1990). A maioria das variedades elite são mais semelhantes do que as novas fontes de germoplasmas que estão sendo exploradas (FULTON et al., 1997).

Estudos com tomate (Lycopersicum esculentum L.) e pimentão (Capsicum annuит L.), utilizando as técnicas de análise multivariada para quantificar a divergência genética, apresentaram concordância satisfatória entre as combinações divergentes e os híbridos superiores (MALUF et al., 1983; MIRANDA et al., 1988). Trabalhando com Capsicum spp., Sudré et al. (2005) demonstraram ser possível quantificar a divergência genética com base em caracteres morfoagronômicos.

Estudos da dissimilaridade de 34 acessos de tomateiro, utilizando as características da fase vegetativa e de produção permitiram, pelo método de Tocher, verificar a consistência dos grupos formados, gerando 12 classes diferentes. Os dois primeiros componentes principais foram suficientes para explicar cerca de $86 \%$ da variação total disponível entre os acessos. As características menos importantes foram número de folhas definitivas e diâmetro do hipocótilo (MARIM et al., 2002).

No Brasil, a caracterização morfológica de Lycopersicon spp. foi realizada pela Embrapa Hortaliças por meio de 38 descritores do IPGRI, contemplando caracteres da planta e do fruto. As informações provenientes da caracterização foram lançadas em bancos de dados computadorizados ("Professional File System"), os quais têm permitido a recuperação de qualquer conjunto de informações de modo simples e eficiente (CARVALHO et al., 1999).

Este trabalho teve como objetivos caracterizar 70 acessos que compõem o Banco de Germoplasma de Lycopersicon esculentum da Universidade Estadual do Norte Fluminense Darcy Ribeiro, utilizando 27 descritores do IPGRI (International Plant Genetic Resources Institute), e quantificar a divergência genética entre os mesmos, por meio de métodos de agrupamento.

\section{MATERIAL E MÉTODOS}

A pesquisa foi desenvolvida na UENF, localizada a $21^{\circ} 45^{\prime}$ de latitude sul, $41^{\circ} 18^{\prime}$ de longitude oeste e 11 metros de altitude, no município de Campos dos Goytacazes, norte do Estado do Rio de Janeiro, durante o ano de 2001.

Os acessos de tomateiro (Lycopersicon esculentum L.) do Banco de Germoplasma da UENF, utilizados neste trabalho, foram cedidos pela Empresa de Pesquisa Agropecuária do Estado do Rio de Janeiro (PESAGRORIO), como parte do Banco Ativo de Germoplama (BAG) de tomateiro mantido pela referida instituição na Estação Experimental de Itaguaí.

A semeadura foi realizada em bandejas de plástico, e, após a germinação, as plântulas foram transferidas para bandejas de poliestireno com 128 células, contendo substrato para a produção de mudas. As plantas no estádio de três a quatro folhas verdadeiras, foram transplantadas para o campo.

Utilizou-se o delineamento experimental em blocos casualizados contendo 70 acessos, três repetições e 16 plantas por parcela. O plantio foi estabelecido em fileiras duplas, espaçadas de 1,2 $\mathrm{m}$ entre linhas e $0,50 \mathrm{~m}$ entre plantas. Tratos culturais recomendados para a cultura foram realizados de acordo com Filgueira (2000).
Com base na recomendação do IPGRI (1996), os descritores de caracterização utilizados foram peso total e peso médio dos frutos; número total e número médio de frutos; diâmetro e comprimento dos frutos, e número de lóculos por fruto. $\mathrm{O}$ descritor número de dias para germinação, apesar de não constar na lista do IPGRI, foi incluído na caracterização.

Como descritores de avaliação foram considerados: número de dias para o florescimento; número de dias para frutificação; número de flores por inflorescência; e teor de sólidos solúveis (medido em ${ }^{\circ}$ Brix, com auxílio de refratômetro).

Realizou-se a análise de variância univariada e, para o estudo da divergência genética entre os acessos, foram empregadas as Análises Multivariadas por meio de Métodos de Agrupamento. Para tanto, foi utilizada a Distância Generalizada de Mahalanobis como medida de dissimilaridade e, para a obtenção dos grupos, utilizou-se o Método Hierárquico do Vizinho Mais Próximo e o Método de Otimização de Tocher. As análises foram conduzidas utilizando-se os recursos computacionais do programa GENES (CRUZ, 2001), seguindo-se os modelos descritos por Cruz e Regazzi (2001).

\section{RESULTADOS E DISCUSSÃO}

As análises de variâncias univariadas revelaram diferenças significativas entre as médias dos acessos em nível de $1 \%$ de probabilidade, pelo teste $\mathrm{F}$, para número total de frutos (NTF), peso total de frutos (PTF), número médio de frutos (NMF), peso médio de frutos (PMF), comprimento do fruto (COM), diâmetro do fruto (DIA), número de dias para germinação (DGE), número de dias para frutificação (DFR), número de flores por inflorescência (NFI), teor de sólidos solúveis (TSS) e número de lóculos por fruto (LOC). Número de dias para o florescimento (DFL) apresentou diferença significativa em nível de 5\% de probabilidade pelo teste F. Estes resultados indicam, para todas as características, a presença de variabilidade entre os acessos.

A análise de agrupamento pelo Método Hierárquico do Vizinho Mais Pró- 


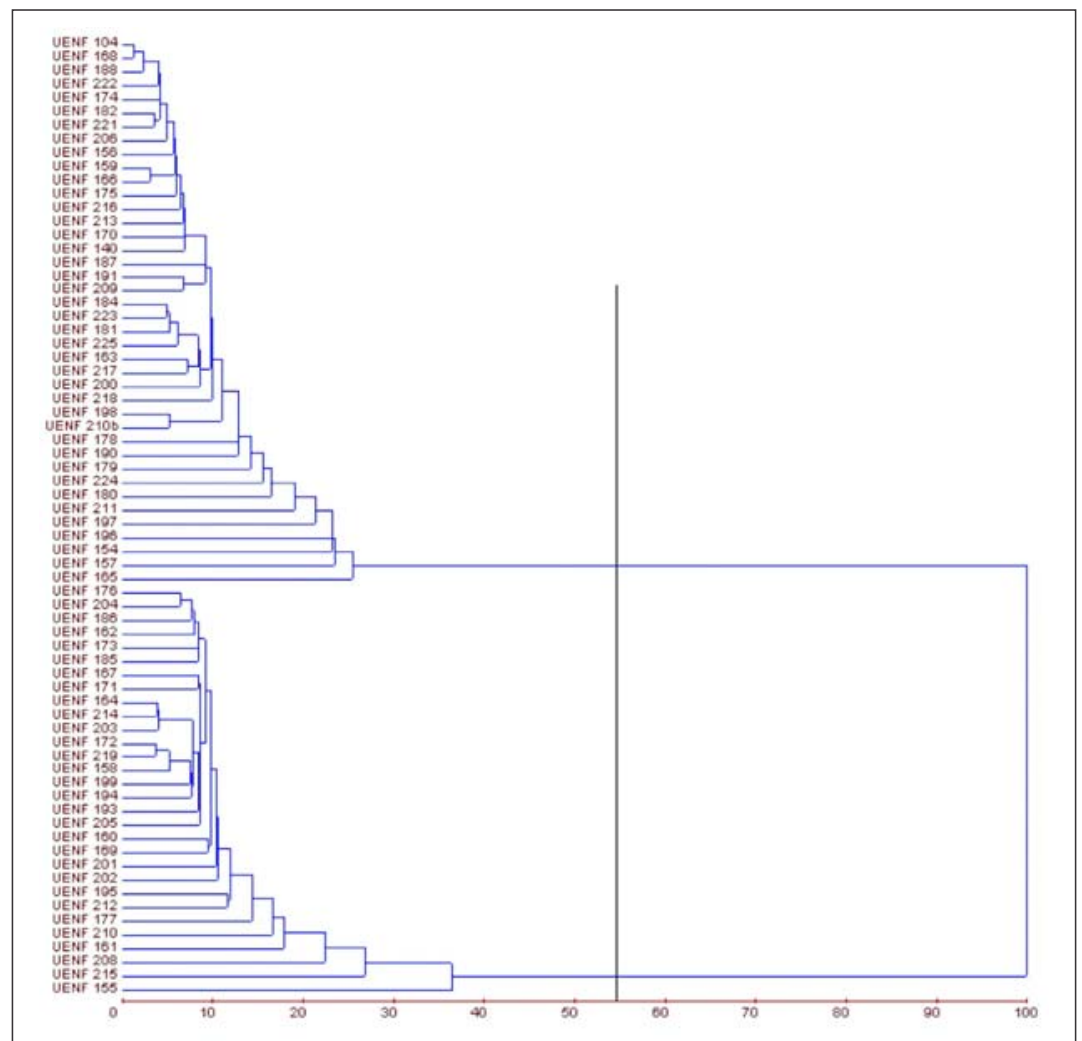

Figura 1. Dendrograma de dissimilaridades genéticas entre 70 genótipos de tomateiro, obtido pelo método "Hierárquico do Vizinho mais Próximo", com base em 12 características quantitativas. Campos dos Goytacazes, UENF, 2001.

ximo, baseada na distância generalizada de Mahalanobis, é subjetiva e pode gerar alguma dificuldade na tomada de decisão quanto ao número de grupos gerados, pois não há um critério definido para determiná-los, e qualquer inferência rígida sobre este número pode não ser produtiva. Por outro lado, a fácil interpretação e simplicidade são importantes nas análises dos dados. Alguns pesquisadores sugerem o estabelecimento de um exame visual de pontos onde ocorram altas mudanças de níveis, possibilitando a delimitação dos grupos (CRUZ, 1990).

Realizando-se o corte do dendrograma (Figura 1) considerando $55 \%$ de dissimilaridade, detectou-se a formação de dois grupos. No grupo 1, estão os acessos com germinação em 10 dias e, no grupo 2, os acessos com sete dias para germinar.

A técnica de agrupamento minimiza a variabilidade dentro do grupo. Entretanto, se a estimativa de distância entre pares de indivíduos dentro do grupo é de elevada magnitude, justifica-se o subagrupamento (ABREU et al., 2004).

Com a finalidade de se obter maiores informações a respeito dos acessos, distribuídos conforme o número de dias para germinação, realizaram-se novas análises de agrupamento dentro de cada grupo, com corte aproximado de 55\%, proporcionando a obtenção de novos subgrupos (Figuras 2 e 3).

Observa-se no dendrograma obtido para o grupo 1 (Figura 2), a formação de sete subgrupos $(1.1,1.2,1.3,1.4,1.5$, 1.6 e 1.7). O subgrupo 1.1 registrou o maior número de acessos, perfazendo um total de 34 genótipos, os quais produziram frutos de tamanho pequeno a intermediário, bi e multiloculados, com variação entre 06 e 52 frutos, peso médio de 11 a 65 g, diâmetro de 25 a 56 mm e 61 a 114 dias para frutificação.

O subgrupo 1.2 foi representado apenas pelo acesso UENF211, que produziu uma média de 08 frutos multiloculados, com tamanho de $31 \mathrm{~mm}$ de comprimento e 51 de diâmetro, com peso médio aproximado de $45 \mathrm{~g}$ e diâmetro de 51,16 mm.

$O$ acesso UENF154 formou o subgrupo 1.3 , produzindo uma média de 44 frutos triloculados, redondos, de tamanho pequeno, com peso médio de $24,38 \mathrm{~g}, 46,52 \mathrm{~mm}$ de diâmetro e frutificação em 107 dias.

Apenas o acesso UENF196 constituiu o subgrupo 1.4 , com média de 06 frutos de tamanho intermediário, multiloculados, peso médio de 75,03 g, diâmetro de 57,69 mm e frutificação em 102 dias.

O subgrupo 1.5 constituiu-se pelo acesso UENF197, que produziu frutos multiloculados, de tamanho intermediário, com peso médio de 89 g, e diâmetro de $60,84 \mathrm{~mm}$.

O subgrupo 1.6 foi composto pelo acesso UENF157, o qual produziu em média 21 frutos biloculados, de tamanho pequeno, apresentando peso médio de 27,40 g, diâmetro de 36,90 mm e 97 dias para frutificação.

O acesso UENF165 ficou isolado no subgrupo 1.7, revelando elevada produção média de frutos (70 frutos), biloculados, de tamanho pequeno, com baixo peso médio $(9,86 \mathrm{~g})$, diâmetro de 29,66 mm e frutificação em 98 dias.

No grupo 2 (Figura 3), formaram-se cinco subgrupos $(2.1,2.2,2.3,2.4$ e 2.5$)$. O subgrupo 2.1 constituiu-se pelo maior número de acessos, totalizando 26 genótipos, os quais apresentaram uma ampla faixa na produção média de frutos, compreendendo valores entre 13 a 75 frutos bi e multiloculados, de tamanho pequeno, com diâmetro variando de 26 a 49 mm e frutificação entre 91 a 107 dias.

Dentro do subgrupo 2.2, o acesso UENF161, único representante, produziu frutos multiloculares, de tamanho intermediário, com 50,8 mm de diâmetro e frutificação em 105 dias. $\mathrm{O}$ acesso UENF210, presente no subgrupo 2.3, produziu 107 frutos de tamanho pequeno, multiloculados, com diâmetro médio de 46,61 mm e 103 dias para frutificação.

Representado pelo acesso UENF155, o subgrupo 2.4 teve produção de frutos pequenos, triloculados, com diâmetro de $25,72 \mathrm{~mm}$ e 92 dias para frutificação. No subgrupo 2.5, com- 
posto pelo acesso UENF208, registrouse a produção de frutos pequenos, multiloculados, com diâmetro chegando a $47 \mathrm{~mm}$ e frutificação em 108 dias.

Conforme Abreu et al. (2002), acessos alocados nos últimos grupos, quando comparados com os primeiros grupos, revelam maior divergência, sendo possível sua utilização em programas de cruzamentos entre grupos mais produtivos.

A análise de agrupamentos pelo Método de Otimização de Tocher possibilitou a formação de onze grupos. O grupo I englobou o maior número de genótipos, totalizando 30 acessos, com germinação em 10 dias, produção entre 09 e 52 frutos bi e multiloculados, peso médio de 11 a 53 g e diâmetro de 25 a 55 mm.

O grupo II foi representado por 22 acessos, os quais tiveram germinação com sete dias, número total de frutos variando entre 13 e 74 frutos, bi, tri e multiloculados, peso médio de 13 a 41 g e 36 a 49 mm de diâmetro.

O grupo III foi composto pelos acessos UENF201, UENF202 e UENF160, que germinaram com sete dias, produziram de 44 a 61 frutos com fenótipo biloculado, com 10 a $13 \mathrm{~g}$ de peso médio e diâmetro de 26 a $33 \mathrm{~mm}$.

Os acessos UENF178, UENF180, UENF197 e UENF196, do grupo IV, germinaram com 10 dias, produziram frutos com peso médio variando entre 37 a 89 g, multiloculados e com 47 a 61 mm de diâmetro.

$\mathrm{O}$ grupo $\mathrm{V}$ foi composto pelos acessos UENF161, UENF210 e UENF208, que apresentaram sete dias para germinação, frutos multiloculados, com peso médio de 25 a 52 g e diâmetro variando entre 47,40 e $52,63 \mathrm{~mm}$.

O grupo VI constituiu-se pelos acessos UENF211 e UENF224, representando os genótipos que germinaram com 10 dias, de frutos multiloculados e que produziram, respectivamente, 08 e 11 frutos por planta, com peso de 44,88 e 64,62 g e diâmetro de 51,16 e 55,98 mm.

Os acessos UENF154 e UENF179, que compõem o grupo VII, germinaram com 10 dias, produziram 44 e 17 frutos biloculados com peso médio de 24,38 e 34,17 g e 46,52 e 42,38 mm de diâmetro, respectivamente.

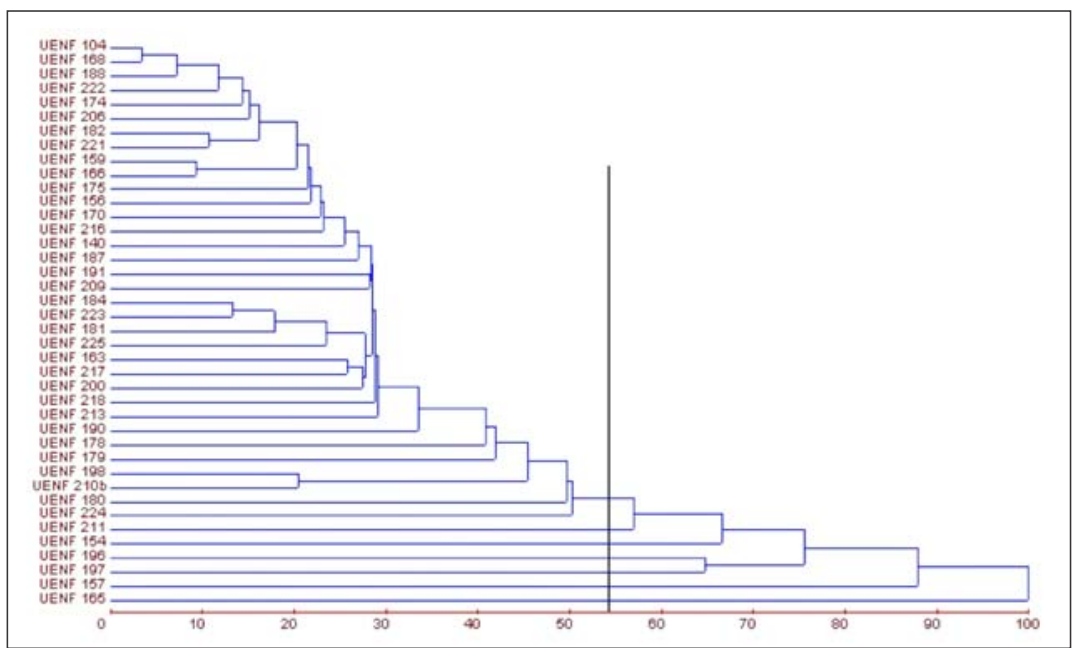

Figura 2. Dendrograma de dissimilaridades genéticas entre 40 genótipos de tomateiro com 10 dias para germinação, obtido pelo método "Hierárquico do Vizinho mais Próximo", com base em 11 características quantitativas. Campos dos Goytacazes, UENF, 2001.

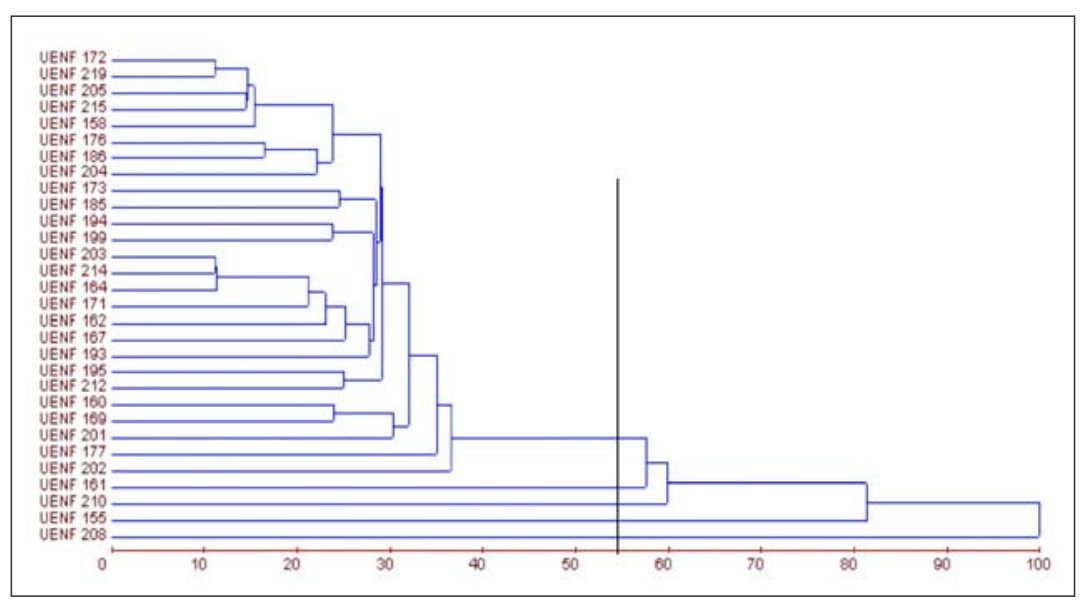

Figura 3. Dendrograma de dissimilaridades genéticas entre 30 genótipos de tomateiro com sete dias para germinação, obtido pelo método "Hierárquico do Vizinho mais Próximo", com base em 11 características quantitativas. Campos dos Goytacazes, UENF, 2001.

O acesso UENF157 único componente do grupo VIII germinou com 10 dias, produziu em média 21 frutos triloculados por planta, com peso médio de 27,40 g e 36,90 mm de diâmetro.

O acesso UENF165 apresentou-se no grupo IX, expressando germinação com 10 dias, produção média de 70 frutos biloculares, com peso médio de 9,86 g e diâmetro de $26,96 \mathrm{~mm}$.

$\mathrm{O}$ grupo $\mathrm{X}$, composto pelo acesso UENF215, germinou com oito dias, produziu em média 22 frutos por planta, com $39 \mathrm{~mm}$ de comprimento, $47 \mathrm{~mm}$ de diâmetro e quatro lóculos.

O acesso UENF155, representante do grupo XI, teve germinação com sete dias, produção média de 90 frutos biloculados, com peso médio de 7,56 g e diâmetro de $25,72 \mathrm{~mm}$.

Comparando-se a formação dos grupos pelos métodos Vizinho Mais Próximo (Figura 1) e Tocher (Tabela 1), observa-se que o grupo I do Vizinho Mais Próximo, obtido pelo agrupamento dos acessos que apresentaram 10 dias para germinação, envolve os grupos I, IV, VI, VII, VIII e IX, gerados pelo método de Tocher. Por outro lado, o grupo II, referente aos acessos com germinação obtida em sete dias, envolve os demais grupos obtidos pelo método de Tocher, quais sejam: II, III, V e X.

Analisando-se os subgrupos obtidos pelo método do Vizinho Mais Próximo, 
Tabela 1. Grupos estabelecidos pelo Método de Otimização de Tocher, com base em 12 características quantitativas avaliadas em 70 genótipos de tomateiro. Campos dos Goytacazes, UENF, 2001.

\begin{tabular}{lc}
\hline Grupos & Acessos \\
\hline & UENF104, UENF168, UENF188, UENF221, UENF174, UENF182, UENF222, \\
I & UENF159, UENF166, UENF206, UENF175, UENF216, UENF156, UENF140, \\
& UENF187, UENF217, UENF209, UENF218, UENF200, UENF225, UENF163, \\
& UENF223, UENF181, UENF191, UENF170, UENF184, UENF213, UENF190, \\
& UENF210b, UENF198 \\
& UENF172, UENF219, UENF158, UENF204, UENF176, UENF205, UENF199, \\
II & UENF214, UENF203, UENF193, UENF164, UENF167, UENF171, UENF186, \\
& UENF212, UENF162, UENF185, UENF195, UENF194, UENF169, UENF173, \\
III & UENF177 \\
IV & UENF201, UENF202, UENF160 \\
V & UENF178, UENF180, UENF197, UENF196 \\
VI & UENF161, UENF210, UENF208 \\
VII & UENF211, UENF224 \\
VIII & UENF154, UENF179 \\
IX & UENF157 \\
$X$ & UENF165 \\
XI & UENF215 \\
\hline
\end{tabular}

formados de acordo com 10 ou sete dias para germinação, e o método de Tocher, observa-se elevada semelhança na formação de grupos. Visualiza-se, pela Figura 2 e Tabela 1, que o subgrupo 1.1 compreende os grupos I e VI de Tocher, envolvendo também os acessos UENF178 e UENF180 do grupo IV.

Os subgrupos $\quad 1.2$ e 1.4 correspondem, respectivamente, aos acessos UENF197 e UENF196 (Figura 2), remanescentes do grupo IV (Tabela 1). Já os acessos UENF154 e UENF157 do grupo VII de Tocher (Tabela 1) foram configurados nos subgrupos $1.3 \mathrm{e}$ 1.5 , respectivamente.

Completando os resultados envolvendo acessos com 10 dias para germinação, verificou-se que os subgrupos 1.6 e 1.7, do Vizinho Mais Próximo (Figura 2), compreendem os respectivos grupos VIII e IX, presentes no método de Tocher (Tabela 1).

Com relação ao subgrupo envolvendo acessos que apresentaram sete dias para germinação (Figura 3), registrouse elevada similaridade em relação aos dados obtidos por Tocher (Tabela 1), sendo que o subgrupo 2.1 envolveu os grupos II e III, enquanto o grupo $\mathrm{X}$ foi representado pelo subgrupo 2.4.

Os acessos UENF161, UENF210 e UENF208, presentes no grupo V (Tabela 1), apresentaram-se isolados nos resultados expressos pela análise do Vizinho Mais Próximo, conferindo a formação dos respectivos subgrupos 2.2, 2.3 e 2.5 (Figura 2).

Os dados obtidos revelaram elevada concordância na formação de grupos método de Tocher quanto pelo Vizinho Mais Próximo. Concordância entre métodos de agrupamento foi verificada para pimentas e pimentões (SUDRÉ et al., 2005), e feijão de vagem (ABREU et al., 2004).

O método do Vizinho Mais Próximo possibilitou a formação de grupos, de acordo com o número de dias para germinação.

Considerando-se que a análise multivariada possibilita a predição da heterose, alguns cruzamentos podem ser sugeridos, seguindo-se o princípio de se cruzar os acessos mais distantes e com melhores características agronômicas (SUDRÉ et al., 2005). Com base nos resultados obtidos neste trabalho, recomendam-se os cruzamentos entre os acessos UENF155 x UENF175 e UENF 155 x UENF222.

\section{AGRADECIMENTOS}

Os autores agradecem a Dra. Maria Luíza de Araújo da Empresa de Pesquisa Agropecuária do Estado do Rio de entre os acessos estudados, tanto pelo
Janeiro (PESAGRO-RIO) pela cessão das sementes dos acessos utilizados neste trabalho e à FAPERJ pela concessão da bolsa para a primeira autora do trabalho.

\section{LITERATURA CITADA}

ABREU, F.B.; MARIM, B.G.; MANDELLI, M.S.; GUIMARÃES, M.A.; BELFORT, G.; SILVA, D.J.H. Divergência genética entre acessos de tomateiro do Banco de Germoplasma de Hortaliças da UFV, baseada em descritores de fruto. Horticultura Brasileira, Brasília, v.20, n.2, jul.2002. Suplemento 2. CD-ROM. Trabalho apresentado no $42^{\circ}$ Congresso Brasileiro de Olericultura, 2002.

ABREU, F.B. LEAL, N.R.; RODRIGUES, R.; AMARAL JR., A.T; SILVA, D.J.H. Divergência genética entre acessos de feijão-de-vagem de crescimento indeterminado. Horticultura Brasileira, Brasília, v.22, n.3, p.547-552, 2004

AGRIANUAL 2002: Anuário da Agricultura Brasileira. São Paulo: FNP Consultoria \& Comércio, 2002. AMARAL JÚNIOR, A.T.; THIÉBAUT, J.T.L. Análise multivariada na avaliação da diversidade em recursos genéticos vegetais. Campos dos Goytacazes - Universidade Estadual do Norte Fluminense - UENF, CCTA, 55 p., 1999.

CARVALHO, S.I.C.; PESSOA, H.B.S.V.; GIORDANO, L.B. Multiplicação, caracterização e conservação da coleção de germoplasma de tomate (Lycopersicon spp.) da EMBRAPA HORTALIÇAS. In: Simpósio de Recursos Genéticos para América Latina e Caribe, 3., 1999, Londrina. Anais..., Londrina: Sirgealc. 1999.

COIMBRA, R.R., MIRANDA, G.V., MOREIRA, G.R., SILVA, D.J.H., CRUZ, C.D., CARNEIRO, P.C.S., SOUZA, L.V., GUIMARÃES, L.J.M., MARCASSO, R.C., CANIATO, F.F. Divergência genética de cultivares de milho baseada em descritores qualitativos. In: Simpósio de Recursos Genéticos para América Latina e Caribe, 3. 2001, Londrina. Anais..., Londrina: Sirgealc. 2001. p. 401-402.

CRUZ, C.D.; REGAZZI, A.J. Modelos biométricos aplicados ao melhoramento Genético. Viçosa: UFV, 390 p., 2001.

CRUZ, C.D. Aplicação de algumas técnicas multivariadas no melhoramento de plantas. 1990. 188 f. (Tese de Doutorado em Genética e Melhoramento de Plantas) - Escola Superior de Agricultura Luiz de Queiroz, Universidade de São Paulo, Piracicaba.

CRUZ, C.D. Programa Genes; versão windows; aplicativo computacional em genética e estatística. Viçosa: UFV, 2001. 648 p.

FILGUEIRA, F.A.R. Novo Manual de Olericultura: Agrotecnologia moderna na reprodução e comercialização de hortaliças. Viçosa: UFV, 2000; 402 p.

FULTON, T.M.; NELSON, J.C.; TANSKLEY, S.D. Introgression and DNA marker analysis of Lycopersicon peruvianum, a wild relative of the cultivated tomato, into Lycopersicon esculentum, followed through three successive backcross generations. Theoretical Applied Genetic, v.95, n.5-6, p.895-902, 1997 
IPGRI. Decriptors for Tomato (Lycopersicon spp.) Roma: Italy, 1996. 44 p.

MALUF, W.R.; FERREIRA, P.E. Análise multivariada da divergência genética em feijãode-vagem (Phaseolus vulgaris L.). Horticultura Brasileira, Brasília, v.1, n.2, p.31-34. 1983.

MARIM, B.G.; ABREU, F.B.; SILVA, D.J.H.; SAMPAIO JÚNIOR, J.D.; GUIMARÃES, M.A.; LUCA, C.A.C. Dissimilaridade entre acessos de tomateiro do Banco de Germoplasma de Hortaliças da UFV, utilizando características da fase vegetativa e de produção. Horticultura Brasileira, Brasília, v.20, n.2, jul. 2002. Suplemento 2. CD-ROM. Trabalho apresentado no $42^{\circ}$ Congresso Brasileiro de Olericultura, 2002.
MILLER, J.; TANKSLEY, S. RFLP analysis of phylogenetic relationships and genetic variation in the genus Lycopersicon. Theoretical Applied Genetics, v.80, p.437-448, 1990.

MIRANDA, J.E.C., COSTA, C.P., CRUZ, C.D.

Correlações genotípica, fenotípica e de ambiente entre caracteres de fruto e planta de pimentão.

Revista Brasileira de Genética, Ribeirão Preto, v.11, n.2, p.457-458, 1988
SUDRÉ, C.P.; RODRIGUES, R.; RIVA, E.M.; KARASAWA, M.; AMARAL JÚNIOR, A.T. Divergência genética entre acessos de pimenta e pimentão utilizando técnicas multivariadas. Horticultura Brasileira, Brasília, v.23, n.1, p.22 27, 2005. 